\section{Vietnam Journal of Agricultural Sciences}

Received: May 26, 2019 Accepted: July 12, 2020

Correspondence to nthyen@vnua.edu.vn

ORCID

Nguyen Thi Hoang Yen https://orcid.org/0000-0001-61490945

\title{
Detection of Ascaris suum in the Livers of Chickens Infected Naturally by the Nested Multiplex PCR Assay
}

\author{
Nguyen Thi Hoang Yen¹, Nguyen Thi Hop ${ }^{2}$, Tran Hai Thanh', \\ Nguyen Van Phuong ${ }^{1}$, Nguyen Thi Hong Chien ${ }^{1}$, Bui Khanh \\ Linh $^{1}$ \& Do Trung Dung ${ }^{2}$ \\ ${ }^{1}$ Faculty of Veterinary Medicine, Vietnam National University of Agriculture, Hanoi \\ 131000 , Vietnam \\ ${ }^{2}$ Department of Parasitology, National Institute of Malariology Parasitology and \\ Entomology, Hanoi 100000, Vietnam
}

\begin{abstract}
This study was conducted to detect Ascaris suum, Toxocara canis, and Toxocara cati in naturally infected chicken livers, and then to provide information related to ascarid infections in humans. Ninetyfour chicken liver samples collected at a fresh market were used for this study. DNA was extracted from each minced liver sample (500 $\mathrm{mg}$ ) by the alkaline lysis method using $\mathrm{NaOH} 50 \mathrm{mM}$ and Tris- $\mathrm{HCl}$ (pH 8.0). The nested multiplex PCR assay using ascarid universal primers was applied to amplify the ITS1 ribosomal RNA gene of $A$. suum, Toxocara canis, and Toxocara cati in all the liver samples. Then, species specific-primers were used to discriminate between $A$. suum and Toxocara spp. The results showed that 2 of the 94 chicken liver samples detected positive for the presence of $A$. suum DNA. This study provided useful information and evidence about $A$. suum infection in humans via exposure to contaminated soil or eating raw/undercooked chicken livers in Vietnam.
\end{abstract}

\section{Keywords}

Ascaris suum, chicken liver, nested multiplex PCR, white spot lesions

\section{Introduction}

Acaris suum, along with Toxocara canis and Toxocara cati, are common roundworms in pig, dog, and cat intestines, and are considered as the causal agents of ascarid larva migrans syndrome (ascarid LMS) in humans. These roundworms have a direct life cycle in which the process of egg embryonation occurs outside in the environment, and they do not need any intermediate hosts to be at an infective stage. Once definitive hosts ingest ascarid embryonated eggs, larvae emerge in the digestive system, penetrate the intestinal wall, and then migrate to the liver via the mesenterial blood veins. 
From the liver, larvae are carried to the lungs using the efferent bloodstream, penetrate the lung alveoli, and then migrate up the respiratory tree. Finally, larvae are coughed up and swallowed by the host to reach the small intestine where they develop into adult worms. The prepatent period is about 6-8 weeks.

Toxocariasis caused by $T$. canis and $T$. cati was first recorded in the $1950 \mathrm{~s}$, followed by $A$. suum infection, and impacts many countries around the world (Beaver et al., 1952; Thompson et al., 1986; Chomel et al., 1993; Magnaval et al., 1993; Maruyama et al., 1996; Sakakibara et al., 2002; Hoenigl et al., 2010; Izumikawa et al., 2011; Penelli et al., 2011; Miller et al., 2015). In Vietnam, some researchers have reported toxocariasis in humans (Tran et al., 2014; Do et al., 2016), however, there has been no information about $A$. suum infection in humans. The migration of ascarid larvae through the human body can cause severe health problems such as eosinophilia, fever, coughing, enlarged liver, or pneumonia (Sakakibara et al., 2002; Izumikawa et al., 2011; Lamberton \& Jourdan, 2015). In some cases, larvae can migrate to the brain or spinal cord causing neuro larva migrans (NLM) (Inatomi et al., 1999; Umehara et al., 2006) or eyes (Glickman et al., 1987). It is called ascarid LMS in humans.

The transmission route of this infection varies in different countries, including either by accidental ingestion of egg embryonates in the soil or contaminated vegetables/drinking water (Matsuyama et al., 1998; Tokojima et al., 2004; Izumikawa et al., 2011); or eating raw/undercook meat and offals contaminated with the larval parasites (Choi et al., 2012). The former methods are considered the main routes in American or Western European countries. By contrast, in East Asian countries such as Japan and South Korea, the later route has recently become more important due to eating habits. In Vietnam, the former routes could be considered as the main methods due to the habit of using pig manure for soil fertilizer in some locations (Vu et al., 2007). However, the latter route has also become a risk because of the culture exchange amongst Asian countries, especially cuisine culture.
Chicken are one of the paratenic hosts of the ascarid roundworm because this roundworm does not develop into adult worms in chickens (Taira et al., 2003; Azizi et al., 2007; Yoshihara et al., 2008). Laboratory experiments of $A$. suum infection in chickens have shown the pattern of ascarid larvae distribution. After hatching in the digestive system, ascarid larvae penetrated the intestinal wall, migrated to the liver, lungs, and eventually back to the liver (for $T$. canis) where they remained in the carcass (for T. cati) (Okoshi \& Ushui, 1968; Taira et al., 2003) or were eliminated from the chicken after 14 days (Yoshihara et al., 2008). However, in natural infections, chickens that are reared freely outside in the environment (free-range chickens) could have a higher risk of getting ascarid eggs from the soil based on their temperament and become a paratenic host for them, especially if pig manure is used for fertilizer ( $\mathrm{Vu}$ et al., 2007). Because of this temperament, soil contaminated with ascarid eggs could be evaluated in addition to the detection of anti-ascarid antibodies in chickens (Campos de silva et al., 2015). Thus, the objectives of this study were to evaluate of the contamination of chicken livers with A. suum, $T$. canis, and T. cati and then provide evidence of ascarid roundworm infections in humans through contact with contaminated soil or eating raw/undercooked chickens in Vietnam.

\section{Materials and Methods}

\section{Parasites}

A. suum, Toxocara canis, and T. cati adult worms were collected from naturally infected pigs, dogs, and cats, respectively, at local abattoirs around Hanoi. They were identified by morphology before performing the next steps. The roundworms were then thoroughly washed in saline solution and male worms were separated and kept in $70 \%$ alcohol for DNA extraction.

\section{Liver samples}

Ninety-four chickens were purchased from a fresh market in Trau Quy Town, Gia Lam district, Hanoi, Vietnam in order to collect the livers from naturally infected chickens. These free-range chickens were reared freely and derived from Hoa Binh, Bac Giang, and Hai 
Duong provinces. The chickens then were necropsied to inspect the macropathology (white spot lesions) on the liver surfaces. Next, the livers were collected for the detection of A. suum by the nested multiplex PCR assay.

\section{DNA extraction}

The genomic DNA was extracted from adult A. suum, T. canis, and T. cati worms using a Blood- Animal- Plant preparation Kit (Jena Bioscience, Germany) following the manufacturer's instructions. DNA concentration was measured by NanoDrop 2000 (ThermoFisher Scientific, US) to detect the presence of DNA.

The alkaline-lysis method was employed for extracting gDNA from the liver tissue. Five hundred milligrams $(500 \mathrm{mg})$ of chicken liver was homogenized in a $15 \mathrm{~mL}$ tube provided by BioMasher (Nippi, Tokyo, Japan), and $1.8 \mathrm{~mL}$ of $50 \mathrm{mM} \mathrm{NaOH}$ was added. After boiling for 30 min, the samples were neutralized by $200 \mu \mathrm{L}$ of $1 \mathrm{M}$ Tris- $\mathrm{HCl}(\mathrm{pH} 8.0)$. The mixture was vortexed thoroughly and centrifuged at $14,000 \times \mathrm{g}$ for $10 \mathrm{~min}$. The supernatant was transferred to a new tube and stored at $-20^{\circ} \mathrm{C}$ until analysis (Nguyen et al., 2016).

\section{Nested multiplex PCR assay}

The nested multiplex PCR assay was applied to amplify a region of the ITS1 ribosomal RNA gene of A. suum, T. canis, and T. cati. The PCR reaction was performed in the total volume of 25 $\mu \mathrm{l}$ containing $1 \mu \mathrm{L}$ of template DNA and the following PCR mixture: $12.5 \mu \mathrm{L}$ Master mix $2 \mathrm{X}$ (Phusa Biochem, Vietnam), $0.75 \mu \mathrm{L}$ of each primer at concentrations of $0.3 \mathrm{mM}$ (Phusa Biochem, Vietnam) and $10 \mu \mathrm{L}$ distilled water. The thermal cycling profile was $94^{\circ} \mathrm{C}$ for $2 \mathrm{~min}$, followed by 40 cycles with denaturation at $94^{\circ} \mathrm{C}$ for $15 \mathrm{~s}$, primer annealing at $52^{\circ} \mathrm{C}$ for $30 \mathrm{~s}$, and extending at $68^{\circ} \mathrm{C}$ for $1 \mathrm{~min}$, and a final elongation step at $72^{\circ} \mathrm{C}$ for $7 \mathrm{~min}$. The first PCR products were used as a template in the speciesspecific nested multiplex PCR, in which multiple primer sets were applied in the same tube with $0.75 \mu \mathrm{L}$ of each of species-specific forward and reverse at concentrations $0.3 \mathrm{mM}$. The PCR conditions were similar to the first reaction, except for primer annealing was at $57^{\circ} \mathrm{C}$ (Table 1) (Wang et al., 2018).

The amplification products were analyzed using $1.0 \%$ agarose gel electrophoresis. The amplification bands were visualized under UV light. A positive reaction was observed when the appearance of the specific sized bands of 208bp, 325bp, and 233bp corresponding with $T$. canis, T. cati, and A. suum, respectively (Wang et al., 2018).

\section{Results and Discussion}

\section{Macroscopic inspection on the liver surfaces}

Most of the collected livers were normal in color and structure. However, 15 of the 94 chickens showed macropathological damage on their livers. White spot lesions ranging from

Table 1. Primer sequences that were used for the nested PCR and nested multiplex PCR (Wang et al., 2018)

\begin{tabular}{ccc}
\hline Primers & \multicolumn{1}{c}{ Sequences } \\
\hline $\begin{array}{c}\text { Ascarid specific universal } \\
\text { Primers (First PCR) }\end{array}$ & Ascarid & $\begin{array}{c}\text { Forward: 5'-CGTCGGTAGCGATGAAAGGT-3' } \\
\text { Reverse: 5'-TTAGTTTCTTTTCCTCCGCT-3' }\end{array}$ \\
& T. canis & $\begin{array}{c}\text { Forward: 5'-CTCGAGTCGACGAAGTATGTAC-3' } \\
\text { Reverse: 5'-AATTGGGCCGCCCATCATAC-3' }\end{array}$ \\
Species-specific primers & T. cati & $\begin{array}{c}\text { Forward: 5'-GTAAGATCGTGGCACGCGTACGTA-3' } \\
\text { (second PCR) }\end{array}$ \\
& Reverse: 5'-TCTTTGATGTCAAGACTTCAGCGC-3' \\
& A. suum & $\begin{array}{c}\text { Forward: 5'-TCAACATTCATAGAGAATGGCATGT-3' } \\
\text { Reverse: 5'-TACATCATTATTGTCACGCTCATCT-3' }\end{array}$ \\
\hline
\end{tabular}




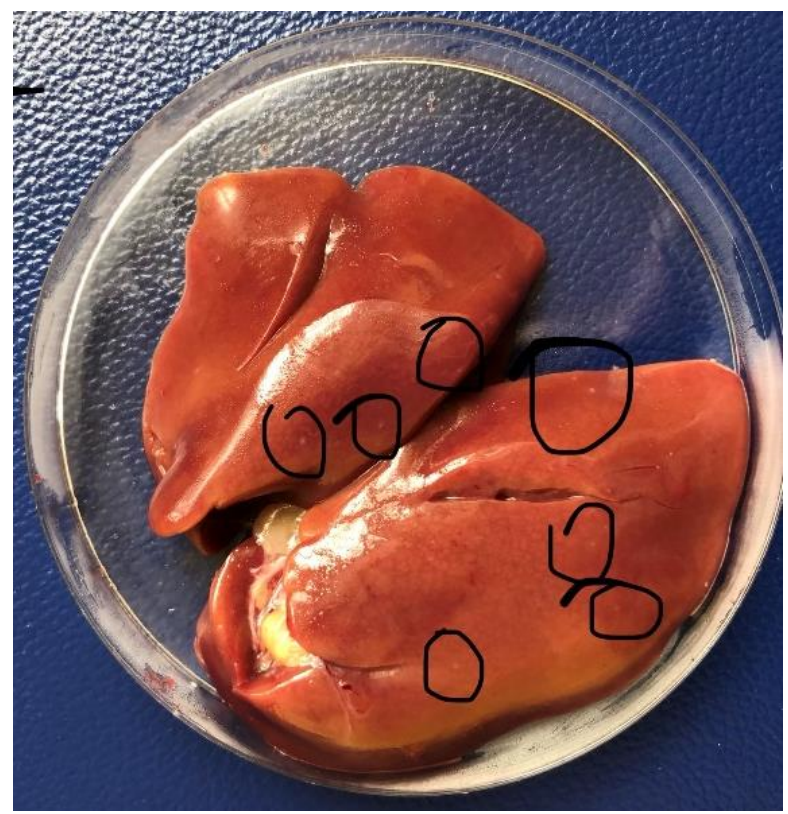

Figure 1. The white spot lesions on chicken livers infected naturally

$1-10$ in number and $0.1-0.5 \mathrm{~mm}$ in diameter were observed on both surfaces of the livers (Figure 1). In addition, several different macropathological features were observed on the liver surfaces, such as damage caused by Marek's disease. However, those samples were excluded from this study.

The observation of white spot lesions on the liver surfaces was one piece of critical evidence of the migration of ascarid larvae through the chicken liver (Taira et al., 2003; Azizi et al., 2007; Yoshihara et al., 2008). However, the white spot lesions were only recognized on day 7 in chickens with double or triple A. suum infections (Yoshihara et al., 2008). White spot lesions were not observed if the chickens were not reinfected or in the cases of early infection (Yoshihara et al., 2008).

In natural infection, chickens can ingest eggs more frequently, leading to a higher chance of larvae presenting in liver. Moreover, raw liver is also a special cuisine in some countries such as Japan and South Korea. This is one of the transmission routes by which humans get ascarid larva migrans syndrome (ascarid LMS) (Choi et al., 2012). Thus, the liver samples were the target of selection for this study.

\section{Detection of $A$. suum in the chicken livers}

Before applying the nested multiplex PCR assay for the naturally infected liver samples, positive control samples (ascarid adult-derived DNA) were successfully amplified. Of the 94 livers collected, two of them were positive and both of them showed amplification of a $233 \mathrm{bp}$ band, which is specific for A. suum (Figure 2). Meanwhile, Toxocara spp. DNA were not detected in this study.

The presence and existence of larvae in the liver depends on each agent. In the cases of $T$. cati and A. suum, the larvae exist in the liver around 14 days after the last experimental infection (Azizi et al., 2007; Yoshihara et al., 2008). For T. canis, after the larvae migrate to the lungs, they migrate back to the liver and exist there for ninety days (Okoshi \& Usui, 1968; Taira et al., 2003). The results of this study showed that the two positive samples of $A$. suum infection were not in livers showing white spot lesions. Thus, the detection of $A$. suum herein illustrated new infections of $A$. suum in those naturally infected chickens. Investigation of several free-range chicken farms showed that the farmers often plant fruit trees such as pomelo trees or litchi trees around and inside chickenrearing areas in order to provide shade for the chickens, and they sometimes used pig manure to fertilize these trees without treatment.

Additionally, chickens were reared in old pigsties in some of the chicken farms (unpublished 


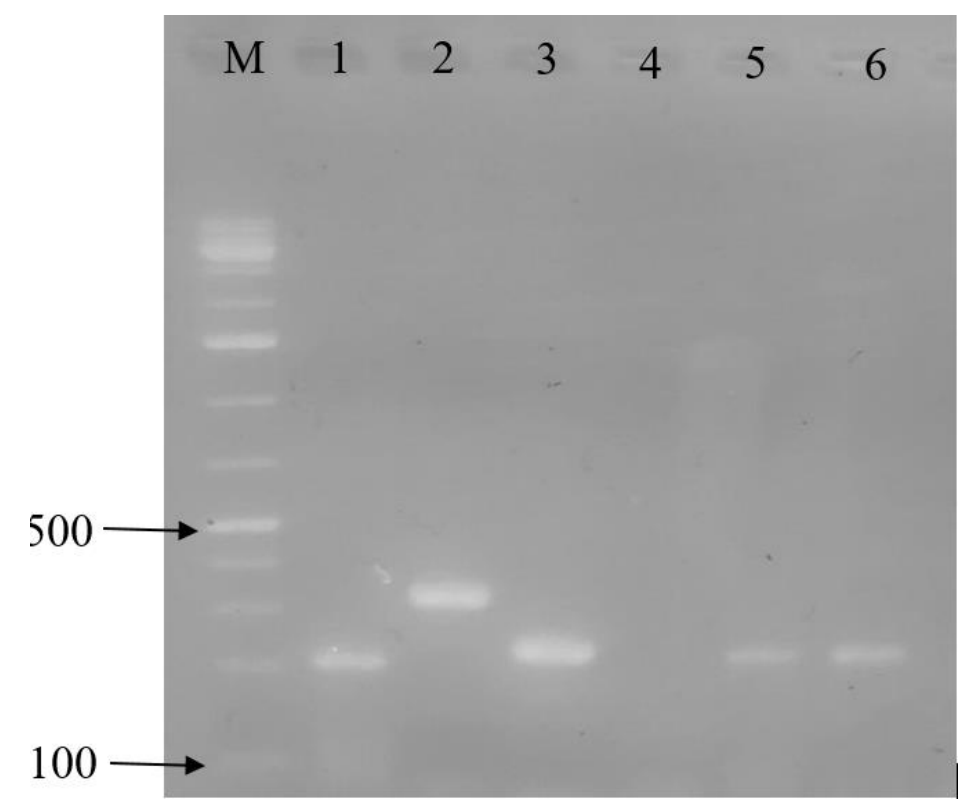

Note: Lane M: 100 bp DNA ladder marker; Lanes 1-3: positive controls (lane 1: T. canis DNA; lane 2: T. cati DNA; lane 3: A. suum DNA); Lane 4: negative control; Lanes 5-6: A. suum DNA liver samples.

Figure 2. The results of Ascaris suum detection in naturally infected chickens

results from another study). Meanwhile, dogs or cats were usually raised outside with no/little chance of invading the chicken-rearing areas. Thus, it is possible that the chance of ingesting $A$. suum eggs was higher than with Toxocara eggs in free-range chickens. Moreover, $T$. malaysiensis was reported in cats in Hanoi (Le et al., 2016). Thus, further studies need to be conducted to clarify this issue.

\section{Conclusions}

The detection of A. suum DNA in naturally infected chicken livers is a direct proof of soil contamination with $A$. suum eggs, but not a direct proof of the infectivity of larvae to a new host. However, the results of this study provided the evidence of chickens ingesting $A$. suum eggs via exposure to contaminated soil. Thus, people need to made aware of the importance of treating pig manure before fertilizing plants, especially those with soilrelated occupations. This paper also provides critical information on the potential evidence of A. suum infections in humans in Vietnam. Further studies need to be conducted to evaluate A. suum infections in humans in this country.

\section{Acknowledgements}

This research was supported by grants from ARES-CCD (Académie de Recherche et d' Enseignement supérieur Wallonie-BruxellesCommission de la Coopération au Développement) in cooperation with Vietnam National University of Agriculture.

\section{References}

Azizi S., Oryan A., Sadjjadi S. M. \& Zibaei M. (2007). Histopathologic changes and larval recovery of Toxocara cati in experimentally infected chickens. Parasitology Research. 102: 47-52.

Beaver P. C, Snyder H., Carrera G. M., Dent J. H. \& Lafferty J. W. (1952). Chronic eosinophilia due to visceral larvae migrans. Pediatrics. 9: 7-19.

Campos-da-Silva D. R., da Paz J. S., Fortunato V. R., Beltrame, M. A., Valli L. C. \& Pereira F. E. (2015). Natural infection of free-range chickens with the ascarid nematode Toxocara sp, Parasitology Research. 114(11): 4289-4293.

Choi D., Lim J. H., Choi D. C., Lee K. S., Paik S. W., Kim S. H. \& Huh S. (2012). Transmission of Toxocara canis via ingestion of raw cow liver: A cross-sectional study in healthy adults. Korean Journal of Parasitology. 50: 23-27.

Chomel B. B., Kasten R., Adams C., Lambillotte D., Theis J., Goldsmith R., Koss J., Chioino C., Widjana D. P. \& Sutisna P. (1993). Serosurvey of some major zoonotic infections in children and teenagers in Bali, 
Indonesia. Southeast Asian Journal of Tropical Medicine Public Health. 24: 321-326.

Do T. D., Tran T. D., Nguyen T. H., Hoang Q. V., Do T. T. T. \& Nguyen T. L. A. (2016). Current status of Toxocara spp. infection in humans in some study sites of Hanoi and Hung Yen, 2014-2015. Journal of Malaria and Parasitic Disease Control. 6(102): 10-16 (in Vietnamese).

Hoenigl M., Valentine T., Zollner-schwetz I., Salzer H. J. F., Raggam R. B., Strenger V. \& Krause R. (2010). Pulmonary ascariasis: Two cases in Austria ANS review of the literature. Wiener klinische Wochenschrift. 122: 94-96.

Inatomi Y., Murakami T., Tokunaga M., Ishiwata K., Nawa Y. \& Uchino M. (1999). Encephalopathy caused by visceral larva migrans due to Ascaris suum. Journal of the Neurological Science. 164: 195-196.

Izumikawa K., Kohno Y., Izumikawa K., Hara H., Hayashi H., Maruyama H. \& Kohno S. (2011). Eosinophilic pneumonia due to visceral larva migrans possibly caused by Ascaris suum: A case report and review of recent literatures. Japanese Journal of Infectious Diseases. 64: 428-432.

Lamberton P. H. L. \& Jourdan P. M. (2015). Human Ascariasis: Diagnostics update. Current Tropical Medicine Reports. 2: 189-200.

Magnaval J. F., Michault A., Calon N. \& Charlet J. P. (1994). Epidemiology of human toxocariasis in La Reunion. Transactions of the Royal Society of Tropical Medicine and Hygiene. 88: 531-533.

Maruyama H., Nawa Y., Noda S., Mimori T. \& Choi W. Y. (1996). An outbreak of visceral larva migrans due to Ascaris suum in Kyushu, Japan. The Lancet. 347: 1766-1767.

Miller L. A., Colby K., Manning S. E., Hoenig D., McEvoy E., Montgomery S. \& Sears S. (2015). Ascariasis in humans and pigs on small-scale farms, maine, USA, 2010-2013. Emerging Infectious Diseases. 21: 332-334.

Le T. H., Nguyen T. L. A., Nguyen T. K., Nguyen T. B. N., Do T. T. T. \& Gasser R. B. (2016). Toxocara malaysiensis infection in domestic cats in Vietnam - A emerging zoonotic issue? Infection, Genetic and Evolution. 37: 94-98.

Nguyen Y. T. H., Wang Z. Z., Maruyama H., Horii Y., Nonaka N. \& Yoshida A. (2016). Evaluation of realtime PCR assay for the detection of Ascaris suum contamination in meat and organ meats. Journal of Food Safety. 37(2): 1-6.

Okoshi S. \& Ushui M. (1968). Experimental Studies on Toxascaris Leonina. VI. Experimental Infection of Mice, Chicken and Earthworms with Toxascaris leonina, Toxocara canis and Toxocara cati. Japanese
Journal of Veterinary Medicine Science. 30: 151-166.

Pinelli E., Herremans T., Harms M. G., Hoek D. \& Kortbeek L. M. (2011). Toxocara and Ascaris seropositivity among patients suspected of visceral and ocular larva migrans in the netherlands: Trends from 1998 to 2009. European Journal of Clinical Microbiology \& Infectious Diseases: Official Publication of the European Society of Clinical Microbiology. 30: 873-879.

Umehara F., Ookatsu H., Hayashi D., Uchida A., Douchi Y., Kawabata H. \& Osame M. (2006). MRI studies of spinal visceral larva migrans syndrome. Journal of Neurological Science. 249: 7-12.

Sakakibara A., Basa K., Niwa S., Yagi T., Wakayama H., Yoshida K. \& Kimura E. (2002). Visceral larva migrans due to Ascaris suum which presented with eosinophilic pneumonia and multiple intra-hepatic lesions with severe eosinophil infiltration- outbreak in a Japanese area other than Kuyshu. Internal Medicine. 41: 574-579.

Taira K., Permin A. \& Kapel C. M. O. (2003). Establishment and migration pattern of Toxocara canis larvae in chickens. Parasitology Research. 90: 521523.

Thompson D. E., Bundy D. A. P., Cooper E. S. \& Schantz P. M. (1986). Epidemiological characteristics of Toxocara canis infection of children in a Carribean community. Bull WHO. 64: 283-290.

Tokojima M., Ashitani J. \& Nakazato M. (2004). A case of eosinophilic pneumonia caused by visceral larva migrans due to Ascaris suum. The Japanese Association for Infectious Diseases. 78: 1036-1040.

Tran T. D. (2014). Actual situation study, some factors has risk to infect larva of Toxocara canis in human and effect of treatment by Albendazole at 2 commune of An Nhon District, Binh Dinh Province (2011-2012). $\mathrm{PhD}$ thesis (in Vietnamese).

Vu T. K. V., Tran M. T. \& Dang T. T. S. (2007). A survey of manure management on pig farms in Northern Viennam. Livestock Science. 112: 288-297.

Wang Z. Z., Shibata M., Nguyen Y. T. H., Hayata Y., Nonaka N., Maruyama H. \& Yoshida A. (2018). Development of nested multiplex polymerase chain reaction (PCR) assay for the detection of Toxocara canis, Toxocara cati and Ascaris suum contamination in meat and organ meats. Parasitology International. 67: 622-628.

Yoshihara S., Hattori J., Nishizono K., Kawamura A., Shimozaki K., Nishida Y. \& Hirayama N. (2008). Hepatic lesions caused by migrating larvae of Ascaris suum in chickens. Journal of Veterinary Medicine Science. 70: 1129-1131. 